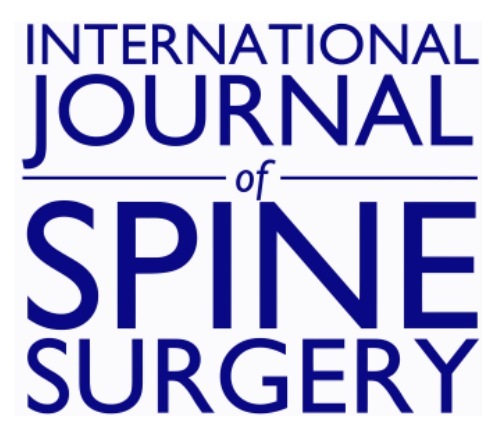

\title{
Letter to the Editor: "Outpatient Minimally Invasive Lumbar Fusion Using Multimodal Analgesic Management in the Ambulatory Surgery Setting"
}

Ellen M. Soffin, Alexander P. Hughes, James D. Beckman, Andrew A. Sama and Frank P. Cammisa

Int J Spine Surg 2021, 15 (5) 848-849

doi: https://doi.org/10.14444/8109

http://ijssurgery.com/content/15/5/848

This information is current as of April 26, 2023.

Email Alerts Receive free email-alerts when new articles cite this article. Sign up at: http://ijssurgery.com/alerts 


\section{Letter to the Editor: "Outpatient Minimally Invasive Lumbar Fusion Using Multimodal Analgesic Management in the Ambulatory Surgery Setting"}

To the editor,

We read with great interest the work by Dr Parrish and colleagues describing their package of multimodal analgesia (MMA) for lumbar surgery in the ambulatory setting. ${ }^{1}$ We applaud their efforts to highlight the importance of adequate analgesia on rapid recovery after spine surgery.

We appreciate that the optimal selection, timing, doses, and combinations of analgesics have not yet been defined in the surgical/anesthetic literature, and institutional preferences will guide the final choices; however, several safety and efficacy questions are raised by the inclusion of some of elements of care in the described work.

Chief among these is the routine administration of preoperative (day of surgery) controlled release oxycodone. Oxycodone controlled release is not approved for preemptive analgesia or for the management of acute postoperative pain unless patients were previously taking the drug. ${ }^{2}$ This prescribing advice was updated during the study period under investigation. Did the authors have a compelling reason to use the drug in an off-label fashion? By reference to Table 1, it does not appear the cohort included patients with chronic pain conditions or with opioid tolerance; indeed, these patients would be less than ideal candidates for surgery in an ambulatory setting. Compounding the risks presented by oxycodone controlled release in opioid-naive patients is the inclusion of pregabalin in the MMA regimen. Longstanding beliefs about the efficacy of gabapentinoids for acute pain reduction and opioid sparing benefits have recently been called into question. ${ }^{3}$ At the same time, evidence of harm from routine perioperative administration has increased. In response to these concerns, the Food and Drug Administration (FDA) issued a warning label update and call for clinical trials on the elevated risk of respiratory depression when gabapentinoids are used in isolation and risk of overdose death when used in combination with opioids. ${ }^{4}$ Given the short length of stay reported in the work, the risk for respiratory depression/overdose death may well peak after the patient has been discharged to home.

Could the authors explain the rationale for coprescribing multiple opioid analgesics in the postoperative period? If we have interpreted Appendix 1 correctly, in addition to preoperative continuous release oxycodone, the MMA package includes tramadol plus oxycodone on the day of surgery, which is transitioned to hydrocodone/paracetamol on postoperative day 1. Guidelines from the FDA as well as the major Pain and Anesthetic Societies continue to recommend against combining opioid medications and against opioids as the basis of MMA. ${ }^{5}$ In our practice, and in several spine care pathways described in the peer-reviewed literature, acetaminophen $( \pm$ nonsteroidal anti-inflammatories) is administered "around-the-clock", and a single opioid is prescribed on an as needed basis, with the dose adjusted by the patient according to their pain scores. ${ }^{6-8}$ The authors' comments regarding patient selection are well received and perhaps account for this choice. However, the generalizability of the MMA described here may be limited, and certainly merits prospective study, compared with more conventional MMA regimens.

These questions highlight the dynamic nature of care pathways and the mandate to update elements as evidence accumulates. Indeed, our group reported favorable outcomes after lumbar fusion when gabapentinoids were included in an enhanced recovery after surgery pathway; however, based on recent riskbenefit analyses, we have now omitted their routine administration. ${ }^{8}$

We hope the authors will comment on any ongoing use of these agents in their MMA. Provocatively, in the 50 patients described here, none suffered serious complications. We thank the authors for this work and look forward to seeing more reports that elevate the care of spine surgery patients.

\section{REFERENCES}

1. Parrish JM, Jenkins NW, Brundage TS, et al. Outpatient minimally invasive lumbar fusion using multimodal analgesic 
management in the ambulatory surgery setting. Int $J$ Spine Surg. 2020;14(6):970-981.

2. US FDA. OXYCONTIN ${ }^{\circledR}$ (oxycodone hydrochloride) extended-release tablets, for oral use. Highlights of prescribing information https://www.fda.gov/media/131026/download. Accessed February 6, 2020.

3. Kharasch ED, Clark D, Kheterpal S. Perioperative gabapentinoids: deflating the bubble. Anesthesiology 2020;133(2):251-254.

4. Arnold N. FDA in brief. FDA requires new warning for gabapentinoids about risk of respiratory depression. December 19, 2019. https://www.fda.gov/news-events/fda-brief/fda-brieffda-requires-new-warnings-gabapentinoids-about-risk-respirato ry-depression. Accessed February 26, 2021.

5. Chou R, Gordon DB, de Leon-Casasola O, et al. Management of postoperative pain: a clinical practice guideline from the American Pain Society, the American Society of Regional Anesthesia and Pain Medicine, and the American Society of Anesthesiologists' Committee on Regional Anesthesia, Executive Committee, and Administrative Council. J Pain 2016;17(2):131-157.

6. Soffin EM, Vaishnav A, Wetmore D, Gang C, Barber L, Beckman JD, et al. Design and implementation of an enhanced recovery after surgery (ERAS) program for minimally invasive lumbar decompression spine surgery: initial experience. Spine (Phila Pa 1976) 2019;44(9):E561-E570.

7. Soffin EM, Freeman C, Hughes AP, Wetmore DS, Memtsoudis SG, Girardi FP, et al. Effects of a multimodal analgesic pathway with transversus abdominis plane block for lumbar spine fusion: a prospective feasibility trial. Eur Spine J. 2019;28(9):2077-2086.

8. Soffin EM, Beckman JD, Tseng A, Zhong H, Huang RC, Urban M, et al. Enhanced recovery after lumbar spine fusion: a randomized controlled trial to assess the quality of patient recovery. Anesthesiology 2020;133(2):350-63.
Ellen M. Soffin, MD, PHD

soffine@hss.edu.

Department of Anesthesiology, Critical Care \& Pain Management, Hospital for Special Surgery, New York, New York

Alexander P. Hughes, MD

Department of Orthopedic Surgery, Spine Service, Hospital for Special Surgery, New York New York

James D. Beckman, MD

Department of Anesthesiology, Critical Care \& Pain Management, Hospital for Special Surgery, New York, New York

Andrew A. Sama, MD

Department of Orthopedic Surgery, Spine Service, Hospital for Special Surgery, New York New York

Frank P. Cammisa, MD

Department of Orthopedic Surgery, Spine Service, Hospital for Special Surgery, New York New York

Published 3 December 2021

This manuscript is generously published free of charge by ISASS, the International Society for the Advancement of Spine Surgery. Copyright (C) 2021 ISASS. To see more or order reprints or permissions, see http://ijssurgery.com. 